JKKP: Jurnal Kesejahteraan Keluarga dan Pendidikan

http://doi.org/10.21009/JKKP

DOI: doi.org/10.21009/JKKP.032.09

E-ISSN: 2597-4521

\title{
PENGARUH KELEKATAN KELUARGA TERHADAP ADVERSITY QUOTIE NT PADA MAHASISWA BIDIK MISI
}

\author{
Hikmatussyarifah 1,a), Uswatun Hasanah 1,b), Tarma ${ }^{1, c)}$

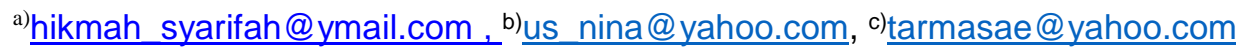

1Program Studi Pendidikan Kesejahteraan Keluarga

Fakultas Teknik, Universitas Negeri J akarta

J In. Rawamangun Muka, J akarta Timur

\begin{abstract}
Abstrak
Adversity quotient adalah suatu kecerdasan dalam menghadapi kesulitaan hidup atau masalah. Seberapa tinggi atau rendahnya tingkat adversity quotient yang dimiliki seseorang akan mempengaruhi bagaimana individu tersebut bisa dengan baik menghadapi kesulitaan hidupnya. Sedangkan dalam penelitian ini data diperoleh dari Humas Bidik Misi sebanyak 2660 mahasiswa yang tercatat sebagai penerima beasiswa bidik misi di Fakultas Teknik, Universitas Negeri Jakarta pada periode angkatan tahun 2012-2015. Dari jumlah tersebut sebanyak 275 mahasiwa tercatat beasiswanya dicabut atau dihentikan. Penelitian ini bertujuan untuk mengetahui pengaruh kelekatan keluarga terhadap adversity quotient. Penelitian ini menggunakan metode survey dengan pendekatan korelasi yang dilakukan pada mahasiswa seluruh Program Studi di Fakultas Teknik, Universitas Negeri Jakarta, Rawamangun, Jakarta Timur. Penelitian ini menggunakan Metode Penelitian Kuantitatif. Populasi pada penelitian ini adalah seluruh mahasiswa Program Studi di Fakultas Teknik, Universitas Negeri Jakarta. Sampel yang digunakan dalam penelitian ini sebanyak 200 orang. Teknik sampling yang digunakan adalah Teknik Purposive Sampling. Hasil dari penelitian ini menunjukan bahwa tidak terdapat pengaruh yang signifikan antara Kelekatan Keluarga terhadap adversity quotient pada mahasiswa Bidik Misi. Kesimpulan dari penelitian ini adalah $\mathrm{H}_{\mathrm{o}}$ diterima, yaitu tidak terdapat pengaruh yang signifikan antara kelekatan keluarga terhadap adversity quotient pada mahasiswa bidik misi. Dari hasil penelitian yang tidak berpengaruh tersebut, jenis kelamin menjadi salah satu faktor penyebab tidak adanya pengaruh kelekatan keluarga terhadap adversity quotient. Karena dapat kita ketahui secara umum anak laki-laki tingkat kelekatan dengan keluarganya tidak terjalin begitu baik.
\end{abstract}

Kata Kunci: kelekatan, keluarga, adversity quotient

\section{The Effect of Family Attachment Against Adversity Question in Bidik Mission Students}

\begin{abstract}
Adversity Quotient is an intelligence in the face of difficulties or problems of life. How high or low levels of adversity quotient of a person will affect how the individual can face the difficulties of life is well. While in this study, the data obtained from public relationship Bidik Mision as many as 2660 student who registered as Bidik Mission scholarship recipients at the Faculty of Engineering, J akarta State University in the period 2012-2015. From that number, 275 students recorded their scholarships has revoked or discontinued. This study aims to determine the effect of family attachment against adversity quotient. This study used survey method with correlation approach. This study used quantitative research methods. The population in this study were all students of
\end{abstract}


the Faculty of Engineering, J akarta State University, Rawamangun, East J akarta. The sample used in this study as many as 200 people. Sampling technique used is purposive sampling technique. The results of this study indicated that there is no significant effect between attachment family against adversity quotient in Bidik Mission students. The conclusion of this study is $\mathrm{Ho}$ is accepted, that is not a significant difference between family attachment against adversity quotient on the Bidik Mission student. Dari hasil penelitian tersebut, jenis kelamin menjadi salah satu faktor dalam ketiadaan pengaruh attachment keluarga terhadap adversity quotient. Karena umumnya, anak dengan tingkat keterikatan keluarganya tidak terikat begitu baik.

Keywords: attachment, family, adversity quotient

\section{PENDAHULUAN}

Adversity quotient (AQ) merupakan bentuk kecerdasan yang melatar belakangi kesuksesan seseorang dalam menghadapi sebuah tantangan disaat terjadi kesulitan atau kegagalan. Penelitian tentang adversity quotient ini, dikembangkan berawal dari keberagaman dunia kerja yang cukup kompleks dengan persaingan yang cukup tinggi, sehingga banyak individu merasa stres menghadapinya.

Individu yang mengalami hal tersebut dikarenakan kendali diri, asal usul dan pengakuan diri, jangkauan, serta daya tahan yang kurang kuat dalam menghadapi kesulitan dan permasalahan yang dirasa cukup sulit dalam hidupnya.Biasanya berakhir dengan kegagalan sehingga menjadi individu yang tidak kreatif dan kurang produktif.

Performansi AQ sebagai kecerdasan yang melatar belakangi kesuksesan dalam menghadapi tantangan setelah terjadi kegagalan, mulai banyak digali dan diteliti khususnya dalam dunia pendidikan saat ini. Banyak para ahli dan pakar pendidikan saat ini mencari dan mencoba mengembangkan pentingnya adversity quotient pada peserta didik sebagai calon individu yang diharapkan menjadi SDM yang tetap kuat berkualitas dan tetap berprestasi dalam bidangnya di masa depan.

Oleh karena itu penulis tertarik untuk coba meneliti dan mendekskripsikan tentang adversity quotient pada mahasiswa penerima beasiswa bidik misi. Banyak faktor yang mempengaruhi adversity quotient dari masing-masing individu, salah satunya adalah kelekatan. Kelekatan adalah ikatan emosional yang dibentuk seorang individu dengan orang lain yang bersifat spesifik, mengikat mereka dalam suatu kedekatan yang bersifat kekal sepanjang waktu. Dalam hal ini hubungan ditunjukkan kepada ibu.Selain ibu, keluarga juga bisa menjadi figur lekat yang sangat berpengaruh pada tingkat emosional anak, dimana keluarga yang memberi dukungan tingkah laku lekat kepada mahasiswa.

Pemerintah melalui Direktorat Jendral Pendidikan Tinggi (Ditjen Dikti) Kementerian Pendidikan Nasional pada tahun 2010. Meluncurkan program Bidik Misi untuk memberikan bantuan biaya penyelenggaraan pendidikan dan bantuan biaya hidup kepada 20.000 mahasiswa yang memiliki potensi akademik memadai dan kurang mampu secara ekonomi di 104 perguruan tinggi penyelenggara.

Data yang penulis dapati dari staff kepengurusan beasiswa bidik misi Pengembang Rektor III, mahasiswa penerima beasiswa bidik misi Universitas Negeri Jakarta yang beasiswanya dicabut dari tahun angkatan 2012-2015 seluruh fakultas yang berjumlah 2.660 mahasiswa yang tercatat beasiswanya dicabut adalah sebanyak 275 mahasiswa. Dari data yang diperoleh terlihat cukup banyaknya jumlah mahasiswa yang beasiswanya dicabut, kemudian penulis mencari tahu masalah apa saja yang dihadapi mahasiswa penerima beasiswa bidik misi sehingga menyebabkan beasiswa yang mereka terima bisa dicabut.

Adapun masalah yang dihadapi mahasiswa penerima beasiswa bidik misi, yaitu penghambatan turunnya dana beasiswa bidik misi yang dikarenakan adanya pergantian atau pencabutan beasiswa pada mahasiswa penerima beasiswa bidik misi,yang ditandai setiap mahasiswa dalam 
jangka waktu dua kali berturut-turut mendapatkan IPK $<2.75$, menikah dan meninggal dunia.Keterkaitannya dengan adversity quotient, bagaimana mahasiswa bisa menghadapi kesulitan yang dalam hal ini adalah untuk mempertahankn IPK yang mereka terima tiap semester guna tetap bisa mempertahankan beasiswa.

Kesulitan mempertahankan IPK disebut karena mahasiswa penerima beasiswa bidik misi pada dasarnya mahasiswa yang berprestasi dan berasal dari keluarga yang kurang mampu, banyak dari mereka yang berusaha membantu keuangan keluarga dengan mencari pekerjaan atau pemasukan tambahan.Adapun mahasiswa penerima beasiswa biasanya dituntut aktif dalam kegiatan organisasi di kampus, banyak dari mereka yang terlalu fokus mengurusi kegiatan organisasinya, apabila mahasiswa tidak bisa mengelola waktu antara kuliah dan kegiatan lain maka berakibat pada nilai IPK yang mereka terima bisa menurun, sehingga beasiswa bidik misi yang mereka terima harus dicabut.

Berdasarkan pembahasan di atas, maka dapat diketahui bahwa diperlukan adversity quotient dalam menganalisis sejauh mana kemampuan mahasiswa berprestasi ini menjadi lebih kuat dalam menghadapi kesulitan dalam hidupnya. Pentingnya penelitian dan pengaruh yang ditimbulkan jika penelitian tidak dilakukan, maka peneliti tertarik untuk meneliti "Pengaruh Kelekatan Keluarga Terhadap Adversity Quotient Pada Mahas iswa Bidik Misi di Fakultas Teknik Universitas Negeri J akarta".

\section{METODOLOGI PENELITIAN}

Tempat penelitian yang dipilih peneliti adalah Fakultas Teknik Universitas Negeri Jakarta. Peneliti memilih lokasi tersebut karena sebelumnya peneliti sudah melakukan wawancara dengan ketua Forum Bidik Misi bahwa, tercatat tingkat dihentikannya beasiswa bidik misi pada mahasiswa di Universitas Negeri Jakarta sangatlah tinggi. Waktu penelitian dimulai sejak bulan Februari 2016 sampai dengan bulan April 2016. Subjek penelitian ini adalah mahasiswa penerima beasiswa bidik misi.

Pada penelitian ini menggunakan penelitian kuantitatif yang meneliti pada populasi atau sampel tertentu, teknik pengambilan sampel pada umumnya dilakukan secara random, pengumpulan data menggunakan instrumen penelitian, analisis data bersifat kuantitatif/statistik dengan tujuan untuk menguji hipotesis yang telah ditetapkan (Sugiyono, 2013) pada penelitian ini, teknik sampling yang digunakan adalah teknik propotionate stratified random sampling.

Pada penelitian ini teknik dan prosedur pengumpulan data yang digunakan yaitu :

1. Angket

Angket kuantitaif dilakukan untuk memperoleh data yang akan mendukung hasil penelitian, yang nantinya data tersebut akan diolah dengan rumus yang sudah ditentukan.

2. Dokumentasi

Dokumentasi merupakan catatan peristiwa yang sudah berlalu. Dokumentasi bisa berupa tulisan, gambar, atau karya-karya menumental dari seseorang. Dokumentasi yang termasuk dalam tulisan misalnya catatan harian, sejarah kehidupan (life histories), cerita, biografi peraturan, dan kebijakan. Dokumentasi yang berupa gambar misalnya, foto, gambar hidup, sketsa dan lain-lain (Sugiyono, 2012: 326). Studi dokumentasi merupakan pelengkap dari penggunaan observasi dan wawancara dalam penelitian kualitatif. Hasil penelitian dari observasi akan lebih kredibel/dapat dipercaya jika didukung dengan sejarah pribadi, masyarakat ataupun aoutobiografi.

\section{HASIL DAN PEMBAHASAN}

Berdasarkan hasil data yang diperoleh pada penelitian ini, menunjukkan thitung Kelekatan Keluarga mempunyai hasil sebesar 0,11 dengan ttabelsebesar 1,971 yang dapat diartikan bahwa 
Kelekatan Keluarga tidak berpengaruh signifikan terhadap Adversity Quotient Pada Mahasiswa. Presentase dimensi Kelekatan Keluarga yang tertinggi terdapat pada secure attachment (kelekatan aman) sebesar $79,34 \%$ dimana hasil tersebut menunjukkan bahwa tidak adanya masalah dalam perhatian orang tua kepada anak. Adanya perasaan aman dalam hubungan dengan figur kedekatannya (Ainsworth dkk, 1978). Presentase sedang dimiliki oleh resistant attachment (kelekatan melawan) sebesar $58,51 \%$ serta presentase terendah dimiliki oleh avoidant attachment (kelekatan menghindar) sebesar 57,78\%. Avoidant attachment (kelekatan menghindar) berada pada tingkat terendah dikarenakan masih banyaknya orang tua yang bersikap tidak peduli terhadap kegiatan dan kebutuhan anaknya.Orang tua dan anak saling menjauh satu sama lain, dimana pengaruh orang tua terhadap anak sedikit, dan bisa timbulnya perilaku kekerasan dan agresif pada masa remaja Ainsworth dalam (Santrock, 2000).

Pola kelekatan dimana orang tua selalu menghindar dari anak mengakibatkan anak melakukan penolakan juga terhadap orang tuanya. Anak tidak memiliki kepercayaan diri karena ketika mencari kasih sayang tidak direspon atau bahkan ditolak. Anak cenderung memenuhi kebutuhan akan afeksi sendiri tanpa bantuan orang tua. Ainsworth dalam (Santrock, 2002) menambahkan bahwa anak yang memiliki pola kelekatan cemas menghindar memperlihatkan ketidakamanan dengan menghindari orang tua.

Orang tua berperan sebagai tokoh penting dengan siapa mahasiswa membangun attachment dan merupakan system dukungan ketika mahasiswa menjajaki suatu duniasosial yang lebih luas dan kompleks (Santrock, 2003). Pada dasawarsa terakhir, para ahli perkembangan mulai mejelajahi peran attachment yang kokoh (secure attachment), dan konsep-konsep terkait seperti attachment dengan orangtua dalam perkembangan mahasiswa. Mereka yakin bahwa attachment dengan orangtua pada masa anak remaja menuju dewasa dapat membantu kompetensi sosial dan kesejahteraan sosial anak itu sendiri, sebagaimana tercermin dalam cirri-ciri seperti harga diri, penyesuaian emosional, dan kesehatan fisik (Allen, dkk, 1994 dalam Santrock, 2003).

Mahasiswa yang memiliki relasi yang nyaman dengan orangtuanya memiliki harga diri dan kesejahteraan emosional yang lebih baik. Dengan demikian, attachment dengan orangtua selama masa remaja menuju dewasa dapat berlaku sebagai fungsi adaptif yang menyediakan landasan kokoh dimana mahasiswa dapat menjelajahi dan menguasai lingkungan-lingkungan baru secara sehat.

Dari hasil penelitian ini, mengapa kelekatan keluarga hasilnya tidak mempengaruhi adversity quotient pada mahasiswa bidik misi, dikarenakan penelitian dilakukan di Fakultas Teknik Universitas Negeri Jakarta yang mayoritas mahasiswanya berjenis kelamin laki-laki. Jadi jenis kelamin responden juga menjadi salah satu faktor yang mempengaruhi kelekatan keluarga terhadap adversity quotient pada mahasiswa, karena kebanyakan mahasiswa laki-laki tidak banyak yang merasakan kelekatan pada orang tuanya dengan baik.

Selanjutnya untuk presentase dimensi Adversity Q uotient yang tertinggi terdapat pada asal-usul dan pengakuan sebesar $80,19 \%$, presentase sedang terdapat pada kendali diri yakni sebesar $70,17 \%$ dan presentase terendah ada pada jangkauan yakni $64,17 \%$, dikarenakan masih banyaknya mahasiswa yang merasakan atau menganggap peristiwa buruk yang terjadi adalah sebuah bencana. Jangkauan (reach) menunjukkan kemampuan dalam melakukan penilaian tentang beban kerja yang menimbulkan stress. Semakin tinggi jangkauan seseorang semakin besar kemungkinannya dalam merespon kesulitan sebagai sesuatu yang spesifik dan terbatas. Semakin efektif dalam menahan atau membatasi jangkauan kesulitan, maka seseorang akan lebih berdaya dan perasaan putus asa atau kurang mampu membedakan hal-hal yang relevan dengan kesulitan yang ada, sehingga ketika memiliki masalah di satu bidang dia tidak harus merasa mengalami kesulitan untuk seluruh aspek kehidupan individu tersebut (Stoltz, 2005)

Hasil korelasi antara variabel $X$ dan $Y$ yakni sebesar $0,01 \%$, dari hasil yang diperoleh tersebut menyatakan lemahnya hubungan antar kedua variabel. Kelekatan keluarga terdapat hubungan yang sangat rendah denganadversity quotient, jika dalam hal ini adalah mahasiswa. Tingkat adversity quotient pada individu sebenarnya muncul dari diri mereka sendiri, bagaimana mereka berpandangan 
bahwa makin besar harapan seseorang terhadap dirinya sendiri, maka makin kuat pula tekadnya untuk meraih kesuksesan dan keberhasilan hidup Mortel dalam (Kusuma, 2004).

Ketekunan dari dalam diri yang dimiliki seseorang akan memberinya daya tahan. Daya tahan tersebut akan membuka kesempatan baginya untuk meraih kesuksesan hidup. Maxwell (Kusuma, 2004) mengatakan bahwa ketekunan yang dimiliki oleh seseorang akan memberinya daya tahan. Daya tahan tersebut akan membuka kesempatan baginya untuk meraih kesuksesan dalam hidup.

Individu yang memiliki kemampuan untuk bertahan dan terus berjuang dengan gigih ketika dihadapkan pada suatu problematika hidup, penuh motivasi, antusiasme, dorongan, ambisi, semangat, serta kegigihan yang tinggi, dipandang sebagai figur yang memiliki adversity quotient yang tinggi, sedangkan individu yang mudah menyerah, pasrah begitu saja pada takdir, pesimistik dan memiliki kecenderungan untuk senantiasa bersikap negatif, dapat dikatakan sebagai individu yang memiliki tingkat adversity quotient yang rendah (Stoltz, 2005).

Didasarkan pada hasil penelitiannya mengemukakan bahwa anak yang ulet adalah seorang perencana, orang yang mampu menyelesaikan masalahnya dan orang yang mampu memanfaatkan peluang. Orang yang mengubah kegagalannya menjadi batu loncatan mampu memandang kekeliruan atau pengalaman negatifnya sebagai bagian dari hidupnya, belajar darinya dan kemudian maju terus (Stoltz, 2005).

\section{KESIMPULAN}

Berdasarkan penjelasan diatas dapat disimpulkan, bahwa kelekatan keluarga bukanlah menjadi salah satu faktor yang mempengaruhi adversity quotient. Faktor terbesar yang mempengaruhi tingkat adversity quotient pada mahasiswa masing- masing, ialah dari dalam diri individu itu sendiri.

\section{SARAN}

Berdasarkan kesimpulan yang telah dikemukakan yakni tidak adanya pengaruh yang signifikan dari variabel kelekatan keluarga terhadap adversity quotient. Maka untuk menerapkan kelekatan keluarga terhadap adversity quotient akan dipaparkan saran, yaitu sebagai berikut :

1. Mahasiswa diharapkan tetap dapat merasakan kelekatan keluarga yang baik guna bisa menjalani aktifitas yang lain dengan dukungan dan pendampingan dari keluarga terutama orang tua. Dalam hal ini agar mahasiswa penerima beasiswa bidik misi yang memiliki masalah dan tidak bisa menyelesaikan masalahnya maka bisa mencari faktor lain yang bisa mendukung atau mempengaruhi tingkat adversity quotient dari masing-masing individu.

2. Peneliti selanjutnya disarankan agar dapat melanjutkan penelitian dengan lebih luas dan mendalam tentang faktor lain yang berhubungan dengan kelekatan keluarga dan adversity quotient. Sehingga hasil penelitiannya dapat dipergunakan untuk memperkaya khasanah ilmu pengetahuan.

\section{DAFTAR PUSTAKA}

Ainsworth, M., Blehar, M., Waters, E., \& Wall, S. 1978. Patterns of Attachment: Assesed in the Strange Situastion and at Home. NJ: Erlbaum. Hillsdale

Kusuma, I.H. 2004. Hubungan antara adversity quotient dan kecerdasan ruhaniah dengan kecenderungan post power syndrome pada TNI. Skripsi. Fakultas Psikologi UMS. Surakarta. Santrock, J.W. 2000. Perkembangan Remaja. Erlangga. Jakarta. 
Santrock, J.W. 2002. Life-Span Development: Perkembangan Masa Hidup (edisi kelima). (Penerj. Achmad Chusairi, Juda Damanik; Ed. Herman Sinaga, Yati Sumiharti). Erlangga. Jakarta.

Santrock, J.W. 2003. Adolescence: Perkembangan Remaja. Edisi Keenam. Erlangga. Jakarta.

Stoltz, P.G. 2005. Adversity Quotient (alih bahasa: T. Hermaya). Grasindo. Jakarta.

Sugiyono. 2012. Metode Penelitian Pendidikan. Alfabeta. Bandung.

Sugiyono. 2013. Metode Penelitian Pendidikan Pendekatan Kuantitatif, Kualitatif, dan R\&D. Alfabeta. Bandung 2008. Metode Penelitian Kuantitatif Kualitatif dan R\&D. Alfabeta. Bandung. 